\title{
Reasonable Arrangement of High-Level Orientation Extraction Boreholes of Pressure Relief Gas in Overlying Strata under High-Strength Fully Mechanized Mining in Low-Gas-Thick-Coal Seam
}

\author{
Han Gao, ${ }^{1,2}$ Xuanping Gong, ${ }^{2}$ Xiaoyu Cheng $\mathbb{D}^{2},{ }^{2}$ Rui Yu, ${ }^{3}$ and Hui Wang ${ }^{4}$ \\ ${ }^{1}$ China University of Mining and Technology (Beijing), Beijing 100083, China \\ ${ }^{2}$ China Coal Energy Research Institute Co., Ltd., Xi'an 710054, China \\ ${ }^{3}$ China Coal Hua Jin Group Co., Ltd., Hejin 043300, China \\ ${ }^{4}$ Shaanxi Qinan Coal Mine Safety Evaluation Services Limited, Xi'an 710054, China \\ Correspondence should be addressed to Xiaoyu Cheng; chengxiaoyu89@126.com
}

Received 5 January 2021; Revised 5 February 2021; Accepted 13 February 2021; Published 2 March 2021

Academic Editor: Gong-Da Wang

Copyright (c) 2021 Han Gao et al. This is an open access article distributed under the Creative Commons Attribution License, which permits unrestricted use, distribution, and reproduction in any medium, provided the original work is properly cited.

In order to solve the problem of pressure relief gas control under high-strength fully mechanized top-coal caving in low-gas-thick-coal seams, this paper studies the evolution of overburden structures and the distribution characteristics of fissure fields during the initial and stable period of working face by physical simulation and numerical analysis. The mathematical model of coupling between mining fracture field and pressure relief gas field is established. The results reveal the distribution characteristics of pressure relief gas field that considers mining-induced fissure field. According to the distribution of mining gas accumulation area, the high directional long boreholes have been put forward to control the pressure relief gas in goafs, and the effect has been tested. The results show that the initial pressure and three periodic pressures occurred from the cutting hole to $135 \mathrm{~m}$ in the initial mining period of the working face. The height of collapse zone developed to $22 \mathrm{~m}$, and fracture height developed to $75 \mathrm{~m}$. The development height of caving zone is stable at $25 \sim 27 \mathrm{~m}$, and the development height of fissure zone is stable at $75 \sim 95 \mathrm{~m}$. The process and distribution of pressure relief gas flow in goaf are obtained by solving the numerical model of pressure relief gas flow in mining fissure field. The gas accumulation area is located within $25 \sim 55 \mathrm{~m}$ from return laneway and 25 50 $\mathrm{m}$ from the roof of coal seam. After the implementation of high directional long drilling gas drainage technology in the initial mining period and the stable mining period, good results have been obtained in the gas control, where the average concentration of gas extraction is $5.8 \%$, the average gas flow rate is $0.71 \mathrm{~m}^{3} / \mathrm{min}$, and the gas concentration in upper corner and return air is less than $0.8 \%$. The results can provide a reference for pressure relief gas control under similar conditions.

\section{Introduction}

At present, the majority of modern mines have gradually realized the high yield and efficiency development of coal resources. High-yield and high-efficiency working faces are mostly distributed in low-gas mines, and the coal mining technologies used are mostly fully mechanized top coal caving $[1,2]$. It is indicated by mining practice that although the coal seam has low gas content, under the condition of high-intensity fully mechanized top coal caving, working face has large amount of gas emission, part gas accumulation, and abnormal or even overrun of gas in the upper corner [3-5], which seriously affects mine safety production. Because of the low gas content and poor permeability in low-gas-thick-coal seam, the effect of predrainage measures in field test coal seam is not good [6-9]. The gas concentration in the working face increases rapidly [10-12]. From this point of view, the pressure relief gas drainage in the mining fissure zone is the key point of the prevention and control of gas under high-strength fully mechanized mining in low-gas-thick-coal seam, and the location of the gas drainage borehole plays an important role 
in the drainage and prevention effect. Therefore, it is necessary to carry out systematic research on the reasonable arrangement of high drilling holes for pressure relief gas drainage under the condition of high-strength fully mechanized caving in low-gas-thick-coal seam.

There are relatively few researches on gas control of high-yield and high-efficiency mining in low-gas-thick-coal seam. At present, the researches are mainly about the cause of abnormal gas outburst in working face, law of gas outburst in fully mechanized top coal caving [13-19], influence of abutment pressure on coal seam gas outburst, influence of overlying strata movement on gas emission in goaf, and integrity and locality gas prevention and control technical measures [20-25]. By means of numerical simulation, Shabanimashcool and $\mathrm{Li}[26]$ studied the variation rule of overlying strata stability under mining in longwall mining face and obtained the distribution characteristics of gas storage and migration channels in fractured zone, which guides mine gas control. Zhang and Huang [27] adopted finite element software COMSOL to research the flow field and gas concentration distribution of working face and goaf in "U"-shaped ventilation system and grasped the gas delivery law in stope. Some achievements have been made in the existing research, but there is a lack of systematic and quantitative research to meet the needs of modern high-yield and high-efficiency mine gas accurate management.

Wangjialing mine of China is a typical high-gas mine caused by high-intensity mining of low-gas-thick-coal seam. It is characterized by low gas content, low air permeability, high mining intensity, and high gas outburst. According to the mining conditions of low-gas-thick-coal seams and fully mechanized top coal caving, this paper starts with basic research, considering the difference of fracture evolution and gas transportation characteristics during the initial mining period and the stable mining period, explores the structure and fracture distribution characteristics of mining overburden rock during the initial mining period and the stable mining period separately, studies gas distribution characteristics of mining-induced fracture field, and distinguishes the distribution of pressure relief gas accumulation area. Accordingly, the reasonable layout design of overburden pressure relief gas drainage is proposed, and the field application and effect test are carried out to solve the problem of gas control under similar conditions and ensure the safe and efficient production of the mine.

\section{Structural Evolution and Fracture Distribution Characteristics of Mining Overburden}

Physical simulation and numerical analysis are used to analyze the structure of overlying strata and fracture evolution law during the working face advancing. Test prototype mine surface elevation is $750 \sim 885.5 \mathrm{~m}$, and workface elevation is $554.6 \sim 582.9 \mathrm{~m}$; as a result, the total thickness of the overlying strata is $278 \mathrm{~m}$. Working face strike length is $1228 \mathrm{~m}$, inclined length is $310 \mathrm{~m}$, and coal seam inclination is $2 \sim 7^{\circ}$. The coal seam is stable, the coal thickness is
$5.90 \sim 6.45 \mathrm{~m}$, the average is $6.2 \mathrm{~m}$, the working face actually enters 8 knives every day, and the ruler is $6.4 \mathrm{~m}$.

The model parameters of physical simulation and numerical analysis are determined by the actual coal and rock geological conditions of the working face. The comprehensive histogram of coal and rock of working face is shown in Table 1. The physical and mechanical parameters of coal and rock are shown in Table 2 . The geometric similarity ratio of the model is $1: 200$; then, according to the similarity criterion, the parameters such as excavation speed and loading load can be obtained. The strike length of the simulated working face is $400 \mathrm{~m}$, and the mining height of the coal seam is $6 \mathrm{~m}$. Each side of the model is provided with $50 \mathrm{~m}$ of protective coal pillars. Step-by-step excavation is used in the strike model, and the advancing speed of the working face is $6 \mathrm{~m} / \mathrm{d}$. A $5 \mathrm{MPa}$ uniform load is applied to the top of model to simulate the stress of overlying strata; meanwhile, the displacement of the left and right and bottom boundary of the model is fixed. The coal rock model of working face is shown in Figure 1.

A total of 9 displacement lines are arranged along the top of the coal seam from bottom to top, $10 \mathrm{~m}, 30 \mathrm{~m}, 40 \mathrm{~m}, 50 \mathrm{~m}$, $60 \mathrm{~m}, 70 \mathrm{~m}, 80 \mathrm{~m}, 90 \mathrm{~m}$, and $100 \mathrm{~m}$, respectively. Each line is equipped with 24 measuring points along the mining direction of coal seam, and the distance between adjacent measuring points is $10 \mathrm{~m}$; a total of 216 displacement measuring points are arranged in the whole model. After each excavation, the fracture and displacement of the mining overburden are recorded, and the overall collapse and displacement of the overlying strata are analyzed with the mining.

2.1. Overlying Strata Structure and Fracture Evolution Law at the Initial Stage of Mining. Figure 2 shows the simulation results of the evolution law of overlying strata structure and fractures during the first weighting and the first three periodic weightings on the working face. When the working face advances to $55 \mathrm{~m}$, the overlying strata of goaf have a wide range of breaking and collapsing phenomena. Many longitudinal fractures of broken stratum are formed, the height of which reaches $25 \mathrm{~m}$, and large space of separated strata is formed (about $5 \mathrm{~m}$ ). The distribution of overlying strata failure presents an ellipse parabola shape; at this time, the first weighting occurs at the working face.

When the working face advances to $85 \mathrm{~m}$, the failure range and height of overlying strata in goaf are further increased, and obvious caving zone, fractured zone, and curve subsidence zone are formed in the height direction. The height of caving zone is about $18 \mathrm{~m}$ and the rock masses on both sides form a hinge structure; besides, the upper strata of the caving zone are relatively complete and longitudinal fractures are developed. The height of the fractured zone reaches $54 \mathrm{~m}$, and the maximum width of the upper separation fracture is $2 \mathrm{~m}$. At this time, the ellipsoidal distribution of overlying strata is more obvious, and the first periodic weighting occurs in the working face.

When the working face advances to $110 \mathrm{~m}$, the height of overburden caving zone in goaf develops to $20 \mathrm{~m}$, and the 
TABLE 1: The comprehensive histogram of coal and rock of working face.

\begin{tabular}{|c|c|c|c|c|c|}
\hline & $\begin{array}{c}\text { Comprehensive } \\
\text { histogram }\end{array}$ & $\begin{array}{c}\text { Serial } \\
\text { number }\end{array}$ & Lithology & Thickness & Ratio \\
\hline 1 & 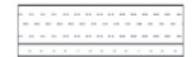 & 1 & Fine grained sandstone & 4.4 & 746 \\
\hline 2 & and & 2 & Medium grain sandstone & 1.46 & 737 \\
\hline 3 & ond & 3 & Siltstone & 25.97 & 728 \\
\hline & 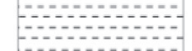 & 4 & Fine grained sandstone & 0.45 & 746 \\
\hline & Gand & 5 & Mudstone & 8.35 & 837 \\
\hline 4 & & 6 & Fine grained sandstone & 4.55 & 746 \\
\hline $\begin{array}{l}5 \\
6\end{array}$ & & 7 & Medium grain sandstone & 1.75 & 737 \\
\hline 7 & and & 8 & Siltstone & 15.5 & 728 \\
\hline 8 & no & 9 & Fine grained sandstone & 2.95 & 746 \\
\hline & and & 10 & Siltstone & 5.75 & 728 \\
\hline $\begin{array}{l}9 \\
10\end{array}$ & (1) & 11 & Fine grained sandstone & 2.5 & 746 \\
\hline $\begin{array}{l}11 \\
12\end{array}$ & 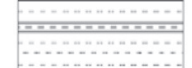 & 12 & Siltstone & 1 & 728 \\
\hline 13 & and & 13 & Fine grained sandstone & 7.5 & 746 \\
\hline $\begin{array}{l}14 \\
15\end{array}$ & ….................. & 14 & Siltstone & 3.58 & 728 \\
\hline 16 & & 15 & Fine grained sandstone & 3.02 & 746 \\
\hline 17 & & 16 & Mudstone & 5.85 & 837 \\
\hline & & 17 & Fine grained sandstone & 10.85 & 746 \\
\hline 18 & & 18 & Medium grain sandstone & 15.8 & 737 \\
\hline & & 19 & Siltstone & 4.21 & 728 \\
\hline $\begin{array}{l}19 \\
20\end{array}$ & (2. & 20 & $1 \#$ Coal & 0.8 & 928 \\
\hline 21 & & 21 & Medium grain sandstone & 15.31 & 737 \\
\hline 22 & & 22 & 2\#Coal & 5.8 & 928 \\
\hline
\end{tabular}

TABLE 2: List of physical and mechanical properties of coal and rock.

\begin{tabular}{|c|c|c|c|c|c|c|c|}
\hline $\begin{array}{l}\text { Serial } \\
\text { number }\end{array}$ & Lithology & $\begin{array}{l}\text { Compressive } \\
\text { strength (MPa) }\end{array}$ & $\begin{array}{c}\text { Tensile } \\
\text { strength }(\mathrm{MPa})\end{array}$ & $\begin{array}{l}\text { Maximum normal } \\
\text { stress (MPa) }\end{array}$ & $\begin{array}{l}\text { Maximum shear } \\
\text { stress }(\mathrm{MPa})\end{array}$ & $\begin{array}{c}\text { Cohesion } \\
(\mathrm{MPa})\end{array}$ & $\begin{array}{l}\text { Density } \\
\left(\mathrm{g} / \mathrm{cm}^{3}\right) \\
\end{array}$ \\
\hline 1 & $\begin{array}{l}\text { Sandy } \\
\text { mudstone }\end{array}$ & 64.0 & 2.19 & 13.7 & 14.8 & 9.65 & 2.635 \\
\hline 2 & $\begin{array}{l}\text { Fine grained } \\
\text { sandstone }\end{array}$ & 58.5 & 2.98 & 13.1 & 13.5 & 8.36 & 2.645 \\
\hline 3 & Mudstone & 62.6 & 2.84 & 13.8 & 14.9 & 7.53 & 2.643 \\
\hline 4 & Siltstone & 55.4 & 2.75 & 13.8 & 15.5 & 10.1 & 2.643 \\
\hline 5 & Coal & 13.0 & 0.88 & 2.85 & 4.41 & 3.2 & 1.301 \\
\hline
\end{tabular}

rock masses on both sides are hinged to form a large space. The height of broken fracture increases to $66 \mathrm{~m}$, and the upper separation space reaches about $3 \mathrm{~m}$. At this time, the second periodic weighting occurs at the working face. When the working face continues to advance to $135 \mathrm{~m}$, the height of overburden caving zone in goaf increases to $22 \mathrm{~m}$, and the height of broken fracture develops to $75 \mathrm{~m}$. The width of the upper bed separated fractures is basically stable. At this time, the third periodic weighting occurs at the working face. Although the scope of overlying strata failure width is further increased, the failure height is basically stable due to the constraint of key stratum.

The vertical displacement distribution of every horizon at overlying strata along strike under different advancing distances at the initial stage of mining is shown in Figure 3. It can be seen from Figure 3 that the vertical displacement of 


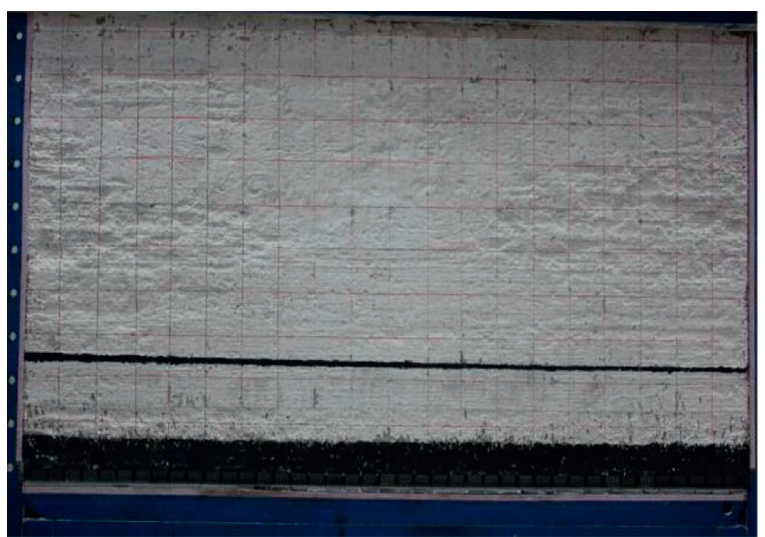

(a)

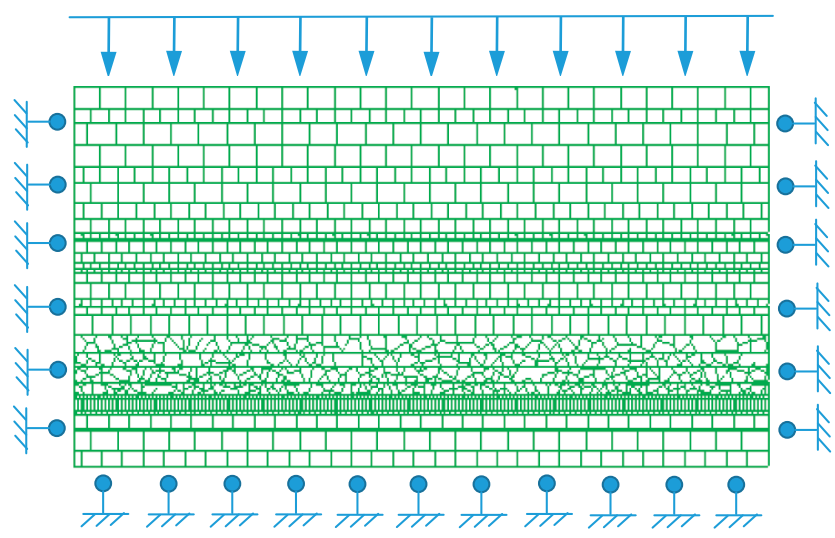

(b)

FIGURE 1: Schematic diagram of the coal and rock model of the working face. (a) Physical model. (b) Numerical model.
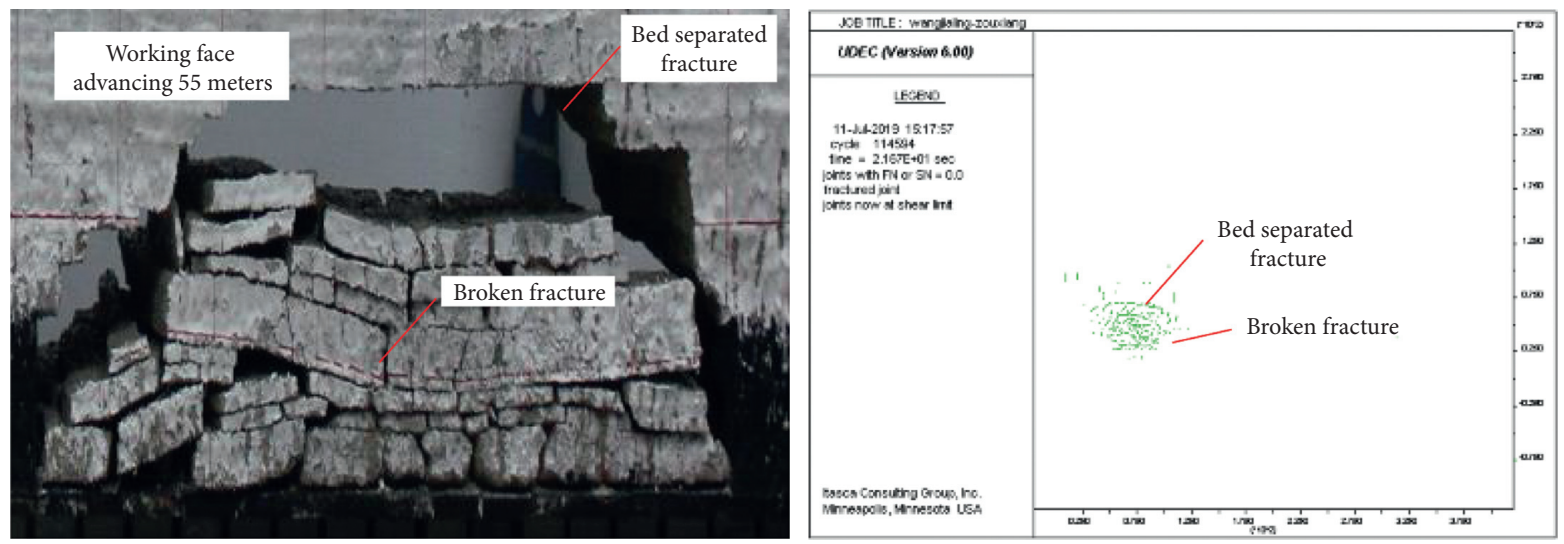

(a)
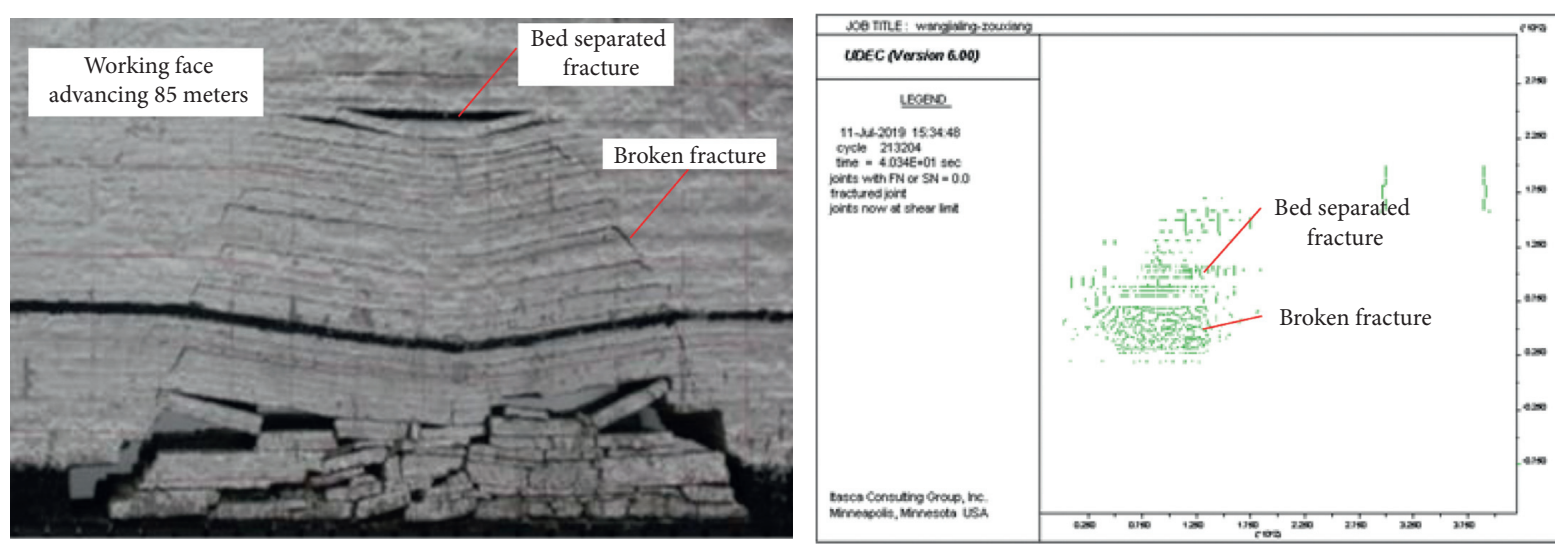

(b)

Figure 2: Continued. 

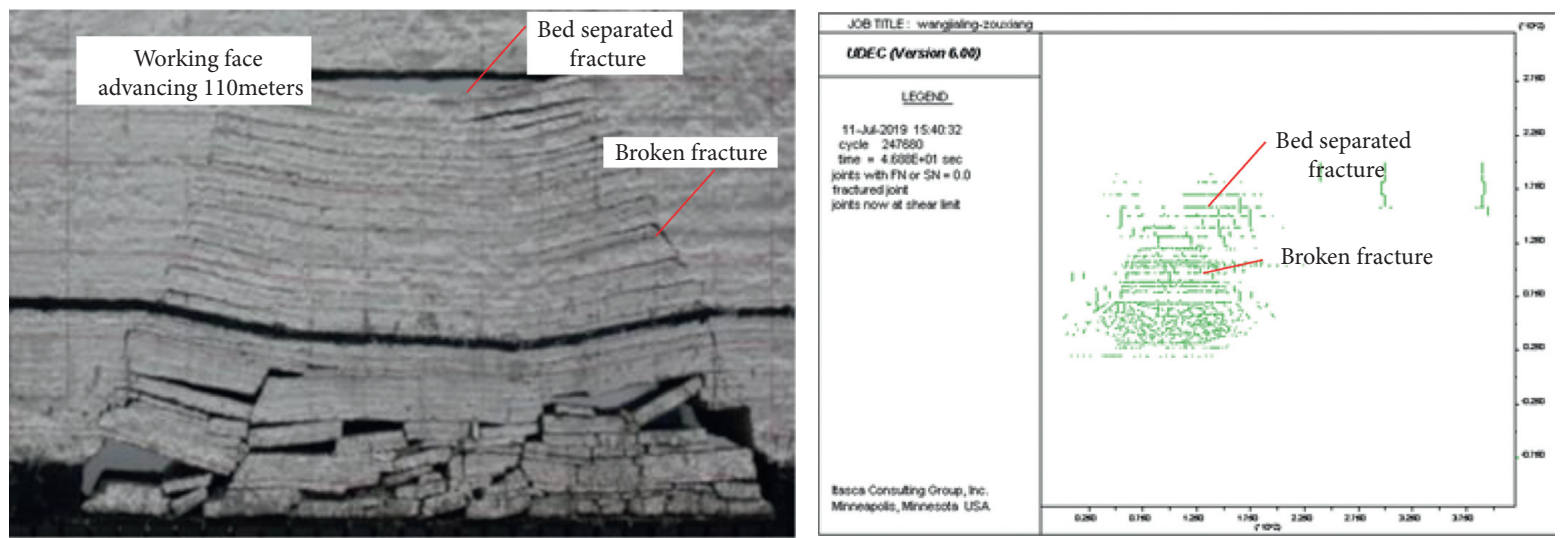

(c)
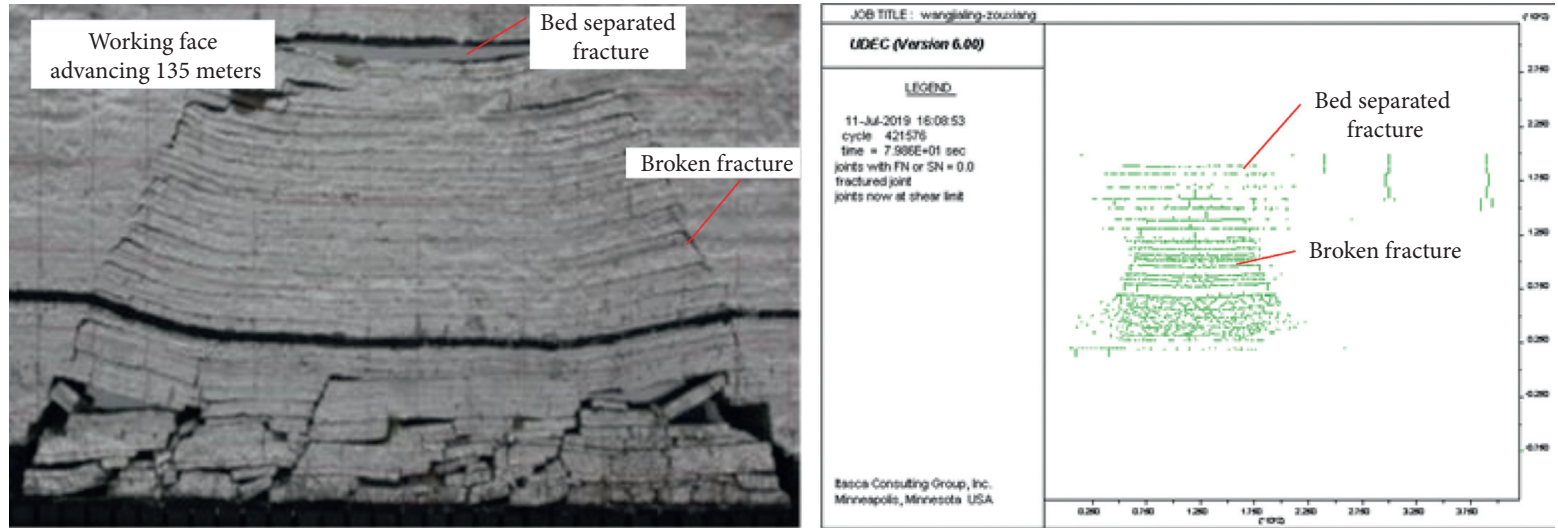

(d)

FIGURE 2: Simulation of overlying strata structure and fracture evolution in the early stage of mining. (a) First weighting of working face. (b) First periodic weighting of working face. (c) Second periodic weighting of working face. (d) Third periodic weighting of working face.

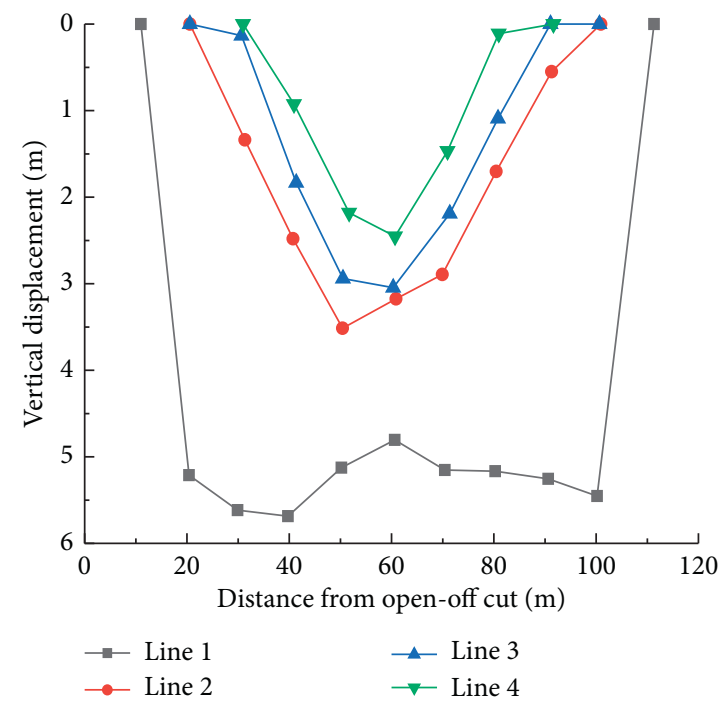

(a)

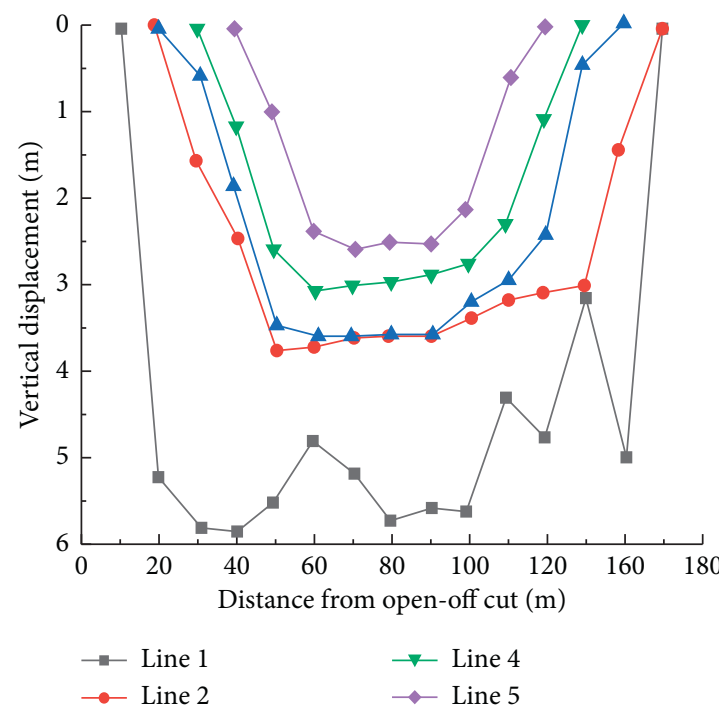

(b)

FIGURE 3: Vertical displacement curve of overlying strata during working face advancing. (a) Working face advancing 85 meters. (b) Working face advancing 135 meters. 
cover rock is nonlinearly asymmetric. Depending on the strata horizon, strength, thickness, and the development of joints, the degree of strata activity is different, and it shows obvious group movement characteristics marked by key stratum; each group of strata has the characteristics of coordinated movement.

The overlying strata undergo continuous dynamic subsidence movement during the working face advancing. In the vertical direction, the overlying strata move more continuously and regularly, and the subsidence decreases gradually. The subsidence of measuring line $1(10 \mathrm{~m}$ away from the coal seam roof) is $5 \sim 5.8 \mathrm{~m}$ in goaf, reaching the maximum value of $5.8 \mathrm{~m}$ under weighting, close to the mining thickness of $6 \mathrm{~m}$, indicating that it is in the compaction area of caving zone. The maximum subsidence of overlying strata in caving zone is basically located at weighting position, and the maximum subsidence of overlying strata in fractured zone is basically located in the middle of goaf. The maximum displacement of line $2(30 \mathrm{~m}$ away from coal seam roof) is $4.5 \mathrm{~m}$, and that of line 5 ( $60 \mathrm{~m}$ away from coal seam roof) is $2.5 \mathrm{~m}$.

\subsection{Distribution Characteristics of Fracture Field of Overlying} Strata in the Stable Mining Period. After three periodic weightings, the overall activity intensity of overlying strata gradually tends to be stable. Under the influence of mining, the overlying strata in goaf are bent, sunk, fractured, and collapsed, forming a mining fracture network composed of a large number of open and closed fractures (Figure 4). The mining-induced fractures are basically distributed axisymmetrically in the form of elliptic projectile. On both sides of the overlying strata in goaf, the open fractures are dominated, and the compaction area in the middle of the overlying strata mainly develops the closed fractures. Large numbers of irregular collapse gaps and fractures are distributed in the lower part of the overlying strata, many longitudinal cracks through strata are distributed on both sides of the middle part of the overlying strata, and transverse bed separated fractures are distributed in the upper part of the overlying strata. Due to the constraint of the key stratum, the bed separated fractures no longer develop upward. In the stable mining period, the development height of caving zone is $25 \sim 27 \mathrm{~m}$, the development height of fractured zone is $75 \sim 95 \mathrm{~m}$, and the development height of curve subsidence zone is about $110 \mathrm{~m}$.

As shown in Figure 5, when the working face advances to $160 \mathrm{~m}$, the maximum displacement of line $1(10 \mathrm{~m}$ away from coal seam roof) has reached $6 \mathrm{~m}$ of coal seam mining height, and the maximum displacement of line $9(100 \mathrm{~m}$ away from coal seam roof) is $0.56 \mathrm{~m}$. When the working face advances to $85 \mathrm{~m}$, the maximum fracture density of the fracture area on one side of the open-off cut reaches 10 strips $/ \mathrm{m}$, and that of the fracture area on one side of the working face reaches 11 strips $/ \mathrm{m}$. As shown in Figure 6 , when the working face advances to $135 \mathrm{~m}$, the maximum fracture density of the fracture area on one side of the open-off cut reaches $10 \mathrm{strips} / \mathrm{m}$, and that of the fracture area on one side of the working face reaches $14 \mathrm{strips} / \mathrm{m}$. The fractures in both sides of the goaf are obviously more than those in the central compaction area, which provides a channel and place for the storage and transportation of pressure relief gas.

\subsection{Fractal Characteristics of Overburden Fracture Field in} Mining Process. Previous studies have obtained the evolution law of mining fractures and the characteristics of overburden "three zones," but the description of the evolution process of fractures is mostly qualitative. In this section, based on the physical simulation results, fractal theory is introduced to quantitatively describe mining fractures by fractal dimension, and the fractal characteristics of mining fracture networks are studied. Fractal theory is mainly used to describe irregular things in nature and give a quantitative standard. The box counting dimension method is widely used because of its convenient and accurate calculation, and it is defined as follows:

$$
D_{b}=\lim _{n \longrightarrow 0} \frac{\ln N n(A)}{\ln \left(2^{n}\right)} .
$$

Let $A \in H\left(R_{m}\right)$, where $R_{m}$ is European space, covered with a closed square box with a side length of $1 / 2^{n}$.

"Fractal Dimension" is fractal dimension calculation software, which can be used to calculate fractal dimension of two-dimensional digital image. The software has the characteristics of convenient operation and fast and accurate calculation. This section is used to calculate the fractal value of mining fracture distribution map. The mining fracture distribution picture is imported into the Fractal Dimension software to obtain $\lg N(\delta)-\lg (1 / \delta)$ double logarithmic map. From the logarithmic curve, the fractal dimension value can be obtained directly, and the fractal dimension data of fracture networks with different propulsion distances are listed in Table 3.

It can be seen from Table 3 that the linear correlation is almost above 0.94 , which indicates that the fracture network distribution of mining rock mass under different propulsion distances has good self-similarity; that is, the fracture network formed under different propulsion distances has fractal characteristics. The slope of straight line is fractal dimension of mining rock mass fracture.

The fracture network is also in a dynamic change in the process of working face propulsion; that is, the fracture network increases gradually and expands forward and upward, and its complexity increases gradually. This is because, with the advance of the working face and the rock collapse, after several periodic pressures, there are constantly new rock strata collapses to cover the old rock layer, and the cracks redevelop.

According to the similar simulation experiment, with the continuous excavation, the fractal dimension of fracture network increases. The relationship between fractal dimension and mining distance during excavation is as follows: 


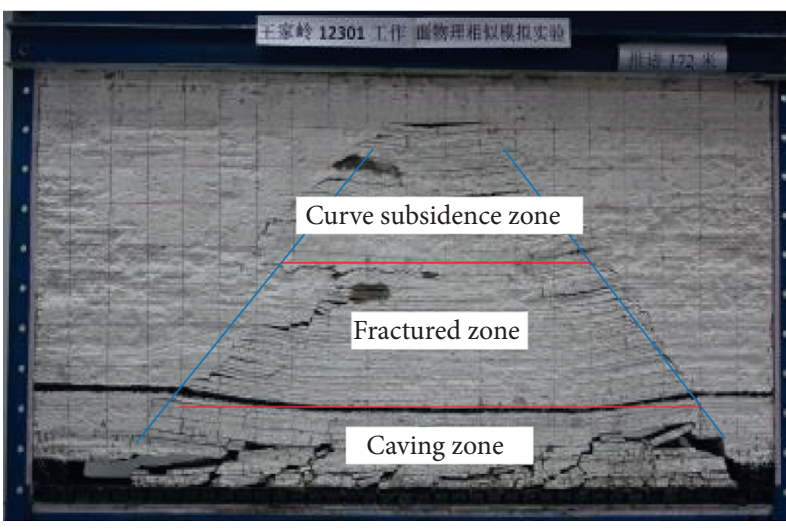

(a)

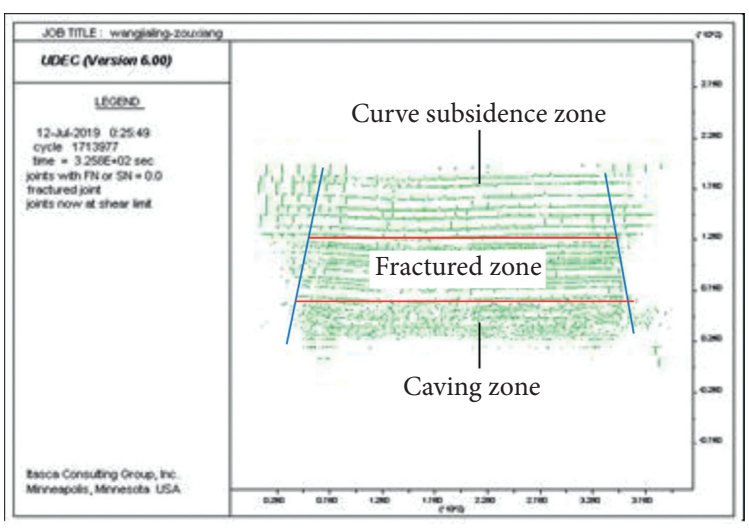

(b)

FIGURE 4: Distribution characteristics of overlying fracture field in stable mining period. (a) Physical simulation. (b) Numerical analysis.

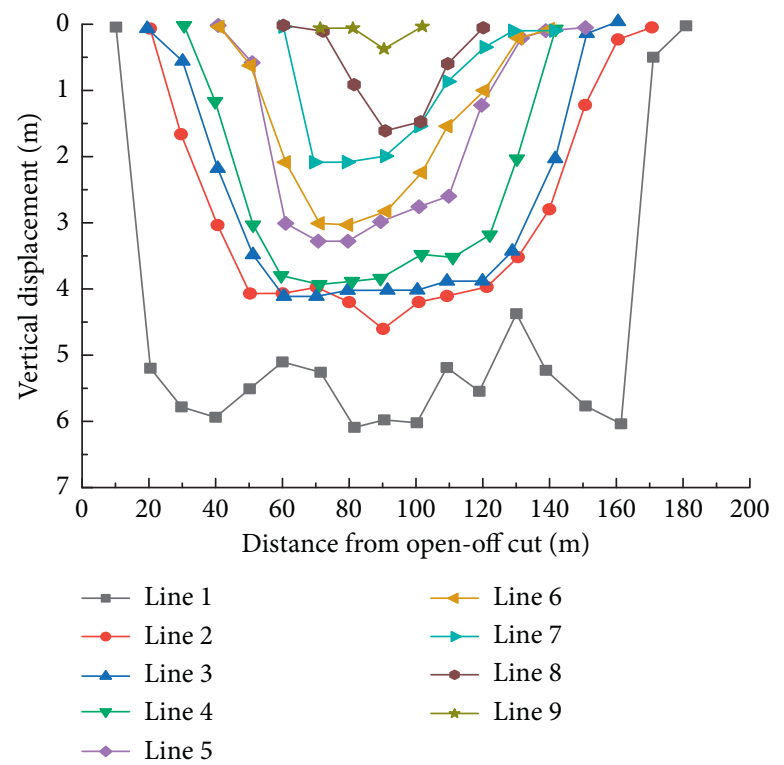

FIGURE 5: Subsidence after working face is advanced to $160 \mathrm{~m}$.

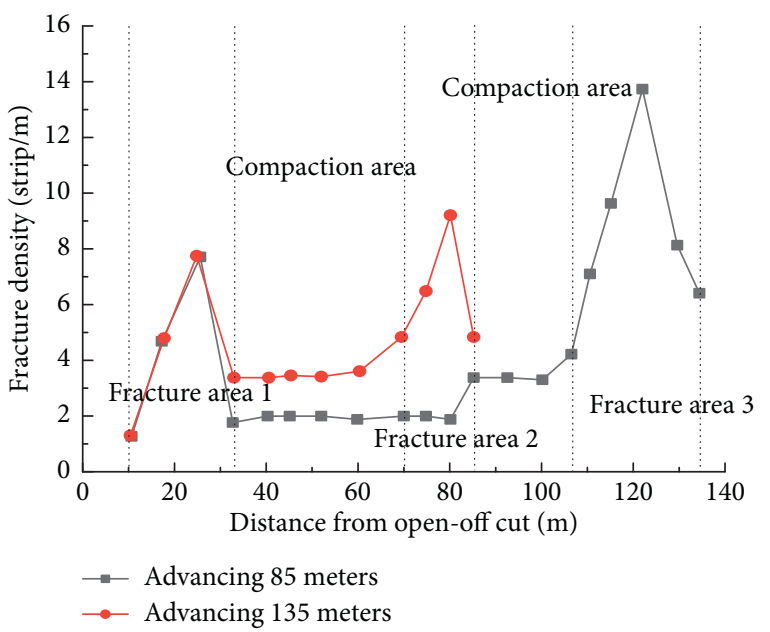

FiguRE 6: Distribution of fracture density of overlying strata from open-off cut to mining face. 
TABLe 3: Calculation of fractal dimension at different propulsion spaces.

\begin{tabular}{lcccc}
\hline $\begin{array}{l}\text { Advance } \\
\text { distance/m }\end{array}$ & Double logarithmic regression linear equation & Fractal dimension & Correlation coefficient & Collapse phase \\
\hline 50 & $y=-1.0230 x+3.3940$ & 1.0230 & 0.9536 & First weighting \\
80 & $y=-1.0938 x+3.6190$ & 1.0309 & 0.9583 & First periodic weighting \\
100 & $y=-1.4030 x+4.5690$ & 1.4030 & 0.9520 & Second periodic weighting \\
130 & $y=-1.5949 x+4.9322$ & 1.5949 & 0.9463 & Third periodic weighting \\
150 & $y=-1.5740 x+4.9997$ & 1.5740 & 0.9494 & Fourth periodic weighting \\
170 & $y=-1.4772 x+4.9397$ & 1.4772 & 0.9545 & Fifth periodic weighting \\
200 & $y=-1.4670 x+5.0603$ & 1.4670 & 0.9571 & Sixth periodic weighting \\
230 & $y=-1.5068 x+5.0956$ & 1.5068 & 0.9554 & Seventh periodic weighting \\
250 & $y=-1.3255 x+4.9830$ & 1.3255 & 0.9630 & Eighth periodic weighting \\
280 & $y=-1.1692 x+4.7656$ & 1.2251 & 0.9649 & Ninth periodic weighting \\
310 & $y=-1.1535 x+4.8586$ & 1.1987 & 0.9669 & Tenth periodic weighting \\
330 & $y=-1.1498 x+4.8838$ & 1.2052 & 0.9669 & Eleventh periodic weighting \\
360 & $y=-1.1232 x+4.8929$ & 1.1765 & 0.9680 & Twelfth periodic weighting \\
\hline
\end{tabular}

$$
\begin{aligned}
D & =\frac{0.13226497 L}{1+0.06328 L} \\
R^{2} & =0.93261
\end{aligned}
$$

From formula (2), it can be seen that the fractal dimension of fracture network increases with the increase of working face advance distance; the whole increase is fast followed by slow increase and then it tends to flatten, and the fractal dimension increases especially when the initial pressure and periodic pressure increase; that is to say, with the advance of working face, new fracture network covers the previous ones, and more developed, which leads to the complexity of the whole fracture situation and the increase of fractal dimension. With the continuous advance of working face, the deep part of goaf is gradually compacted, the fissure tends to close, and the fissure is attached to the working face. The evolution of near overburden produces new fissures, so that the closed fissures and the new fissures are in a dynamic equilibrium process, especially in the state of relative stability of fractal dimension after the fourth periodic weighting.

\section{The Coupled Mathematical Model of Mining Fracture Field and Pressure Relief Gas Field}

In order to further study the distribution characteristics of pressure relief gas field in mining fracture field, it is necessary to construct a mathematical model of gas flow in mining fracture field [28]. The mathematical model of pressure relief gas flow in mining fracture field includes the equation of state, continuity, mass conservation, motion, migration, and diffusion as follows.

3.1. Gas Flow State Equation. It is usually assumed that the gas flow is an isothermal process according to the ideal gas equation of state:

$$
\frac{\rho}{\rho_{0}}=\left(\frac{p}{p_{0}}\right)\left(\frac{z_{0} T_{0}}{z T}\right) .
$$

In the formula, $T$ is gas absolute temperature; $T_{0}$ is fissures absolute temperature; $z$ is compression factor; $p$ is gas pressure; $z_{0}$ is gas compression factor in fractures; $p_{0}$ is gas pressure in fissures.

3.2. Gas Flow Continuity Equation. Take a micronome, as shown in Figure 7. After $\triangle \mathrm{t}$ time, the change of mass of microelement is

$$
\Delta M_{1}=\frac{\partial \rho \phi}{\partial t} \mathrm{~d} x \mathrm{~d} y \mathrm{~d} z \Delta t
$$

The mass difference between gas inflow and outflow in the microelement is

$$
\begin{aligned}
\Delta M_{2} & =\Delta M_{x}+\Delta M_{y}+\Delta M_{z} \\
& =-\left(\frac{\partial \rho v_{x}}{\partial x}+\frac{\partial \rho v_{y}}{\partial y}+\frac{\partial \rho v_{z}}{\partial z}\right) \mathrm{d} x \mathrm{~d} y \mathrm{~d} z \Delta t
\end{aligned}
$$

According to the principle of mass conservation, the continuity equation of seepage flow in fracture field of mining overburden rock can be obtained:

$$
\frac{\partial(\rho \phi)}{\partial t}+\nabla(\rho v)=0
$$

3.3. Gas Flow Mass Conservation Equation. The gas flow in the overlying rock mining fissure field needs to satisfy the conservation equation of gas flow mass, which indicates that the change of gas mass per unit time is equal to the sum of the net diffusion flows through the interface of microelement:

$$
\frac{\partial \rho c}{\partial t}+\frac{\partial}{\partial x_{i}}\left(\rho c u_{i}\right)=-\frac{\partial}{\partial x_{i}}\left(J_{g} u_{i}\right)+S_{g} .
$$

In the formula, $u_{i}$ is mean flow rate; $S_{g}$ is additional generation rate for source term; and $J_{g}$ is diffusion flux.

3.4. Gas Flow Motion Equation. The gas flow law is different in different regions of the fracture field of mining overburden, so different theoretical models of gas flow should be selected to describe it. Here, it is assumed that the gas flow 


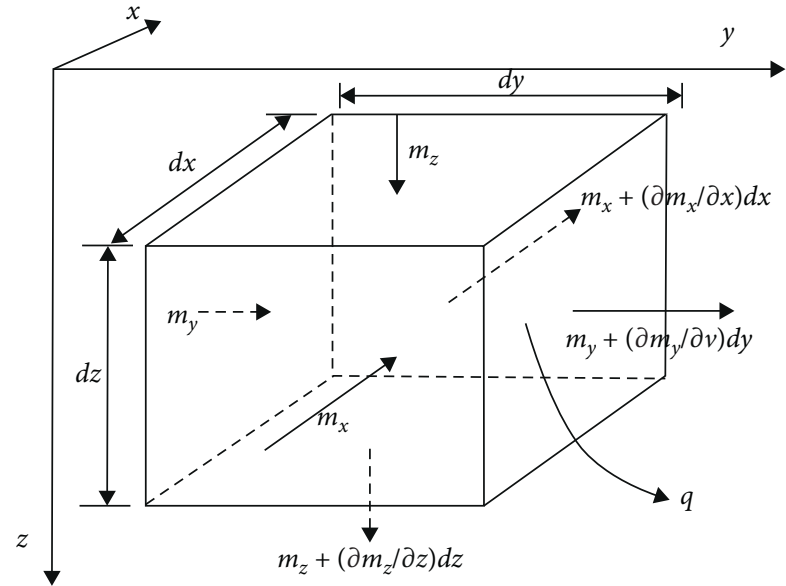

Figure 7: Mass conservation of microelement.

state of the closed fissure in the fracture field is Darcy seepage, and the gas flow conforms to the description of Darcy's law of fracture flow. The gas flow in the area of separated fissure space is turbulent and solved by NavierStokes motion equation.

The governing equation of the internal solution domain of the fracture flow equation is as follows:

$$
\rho S \frac{\partial p}{\partial t}+\nabla \rho\left[\frac{k}{\mu}(\nabla p+\rho g \nabla D)\right] .
$$

The control equation of fracture flow is as follows:

$$
d_{f} \frac{\partial}{\partial t}\left(\varepsilon_{f} \rho\right)+\nabla_{T}\left(\rho q_{f}\right)=d_{f} Q_{m} .
$$

In the formula, $\varepsilon_{f}$ is fissure porosity; $Q_{m}$ is mass source; $q_{f}$ is volume flow per unit length in fissures; $\mu$ is fluid viscosity; $d_{f}$ is fissure width; $p$ is fluid pressure; $\rho$ is fluid density; and $\nabla T$ is gradient on fracture section.

The dependent variables of the Navier-Stokes equation are velocity vector $u_{c}$ and pressure $p$, and the solution and control equation is as follows:

$$
\rho \frac{\partial u_{c}}{\partial t}+\left(\rho u_{c} \cdot \nabla\right) u_{c}=-\nabla p+\nabla\left[\eta\left(\nabla u_{c}+\left(\nabla u_{c}\right)^{T}\right)\right]+F .
$$

In the formula, $\eta$ is viscosity coefficient; $u_{c}$ is velocity vector; and $F$ is custom external volumetric force.

3.5. Gas Migration and Diffusion Equation. The above equation does not consider the nature of gas diffusion and migration, but the migration law of pressure relief gas in porous media can be described by the convection-diffusion equation of porous media:

$$
\theta_{s} \frac{\partial c}{\partial t}+\nabla\left(-\theta_{s} D_{L} \nabla c+u c\right)=S_{c}
$$

In the formula, $\theta_{s}$ is fluid volume rate; $c$ is concentration; $D_{L}$ is pressure diffusion tensor; and $S_{c}$ is relative gas emission velocity.
The above formulas constitute the mathematical model of gas flow in mining fracture field. It can be seen that the mathematical model of pressure relief gas flow in mining fracture field is constructed by using Darcy fracture flow equation and Navier-Stokes equation. The pressure field distribution and velocity field distribution in the process of pressure relief gas flow in goaf can be obtained by solving the model. At the same time, the pressure relief gas flow has the characteristics of rising and floating diffusion, and the gas seepage occurs at the same time. This process is described by the convection diffusion equation of porous media. Gas migration is a multifield coupling process; by using multiphysical field coupling software COMSOL, the law of gas migration in fracture field is studied, and the gas enrichment area is explored to provide guidance for the design of gas drainage arrangement in fracture field.

\section{Distribution Characteristics of Pressure Relief Gas Field considering Mining-Induced Fracture Field}

4.1. Establishment of Solid-Gas Coupling Numerical Model. Based on the numerical simulation results of mining-induced fracture field evolution in the overlying strata, the corelDRAW software is used to extract the mining fracture, and the extracted fracture field is imported into COMSOL software to establish the solid-gas coupling numerical calculation model and conduct meshing, as shown in Figure 8.

According to the actual situation of the mine and referring to the empirical range of permeability of various rock masses, the permeability of rock mass is $1 \times 10^{-10} \mathrm{~m}^{2}$, and the porosity is 0.01 ; the permeability of closed fracture is $1 \times 10^{-5} \mathrm{~m}^{2}$, and the porosity is 0.1 ; the space permeability of separation layer is $1 \times 10^{-2} \mathrm{~m}^{2}$, and the porosity is 0.8 . The gas pressure at the coal wall at both ends of the working face is $0.2 \mathrm{MPa}$, and the gas pressure of residual coal in goaf is not included. In addition, it is considered that there is no gas in the fracture field at the initial time; namely, the initial gas pressure and concentration are both 0 . The mass source of the coal wall area at both ends of the working face is $6 \times 10^{-3} \mathrm{~kg} /\left(\mathrm{m}^{3} \cdot \mathrm{s}\right)$, and that of the goaf is $5 \times 10^{-4} \mathrm{~kg} /\left(\mathrm{m}^{3} \cdot \mathrm{s}\right)$.

4.2. Gas Distribution and Variation Characteristics of MiningInduced Fracture Field. Figure 9 shows the simulation results of gas concentration distribution and variation considering mining-induced fracture field. It can be seen from the figure that, affected by the gas concentration and pressure difference, the gushing gas penetrates and migrates in the mining-induced fractures and rock mass. Because of the high permeability of fractures, the gas mainly diffuses in the fractures, and the mining-induced fractures play an important role in gas migration and distribution.

At first, the gas was mainly distributed in the side near the return airway, and it accumulates in small scale in the upper corner area. As time goes on, the gas concentration on one side of the intake airway increases gradually. Under the 


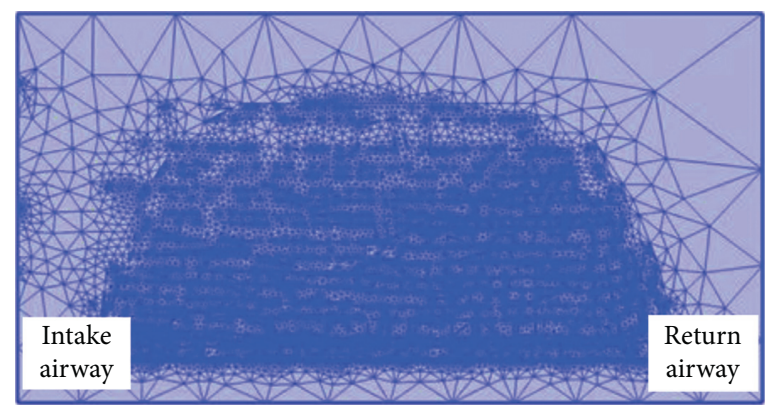

FIgURE 8: Network partition diagram of mining fracture field model.

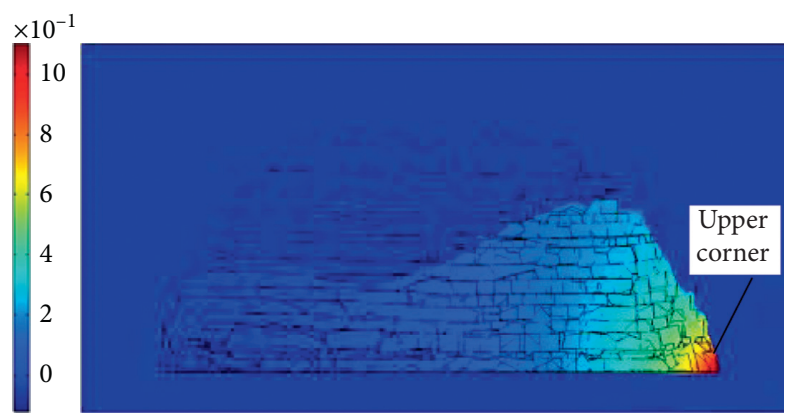

(a)

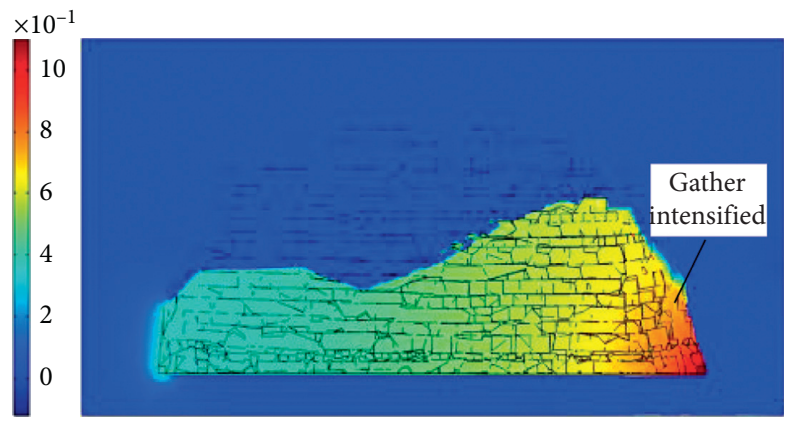

(c)

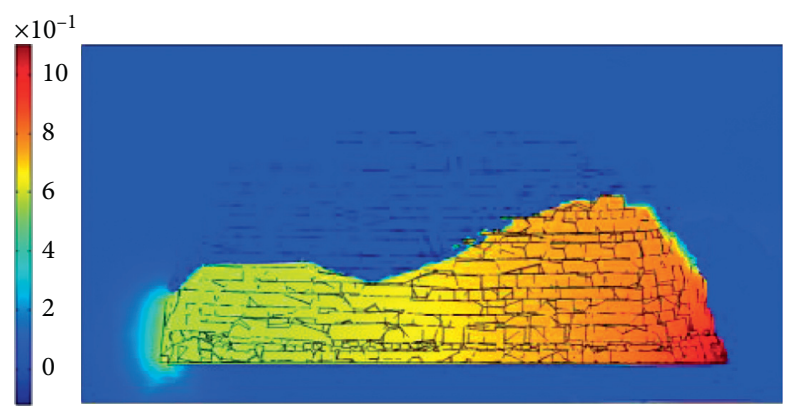

(e)

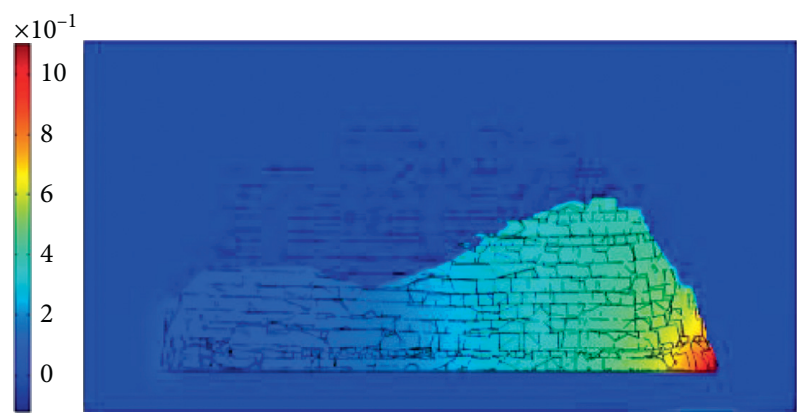

(b)

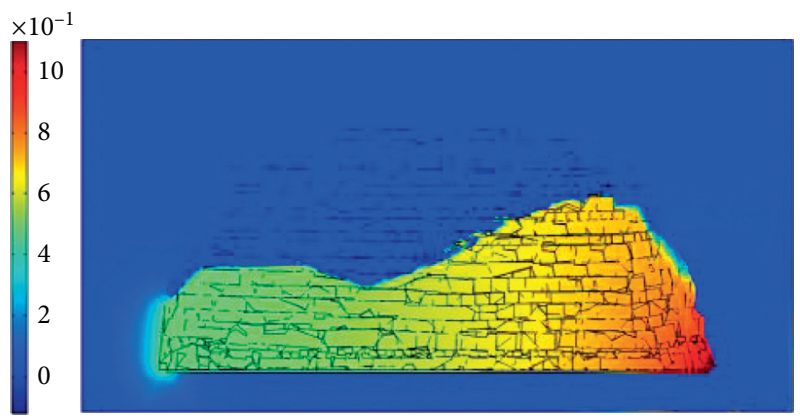

(d)

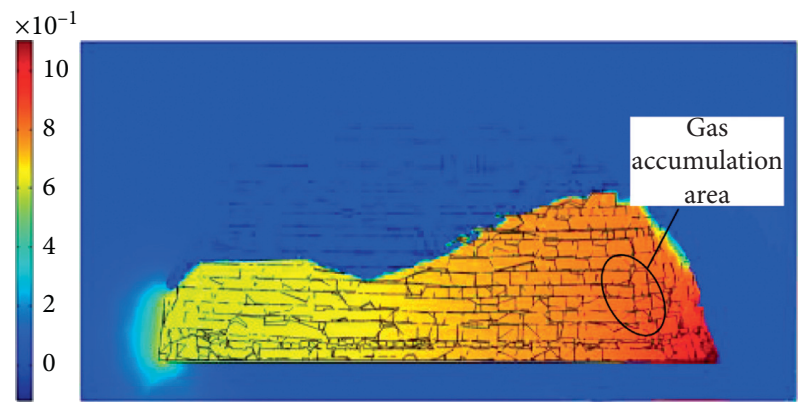

(f)

FiguRE 9: Distribution and variation of gas concentration in fracture field. (a) $t=10 \mathrm{~h}$. (b) $t=20 \mathrm{~h}$. (c) $t=50 \mathrm{~h}$. (d) $t=60 \mathrm{~h}$. (e) $t=90 \mathrm{~h}$. (f) $t=100 \mathrm{~h}$.

influence of air flow, the gas concentration on one side of the return airway is significantly higher than that on the other side of the intake airway, and the gas accumulation area in the upper corner increases rapidly, forming a high concentration gas accumulation area. The distribution characteristics of gas field in mining overburden fractured zone are 
saddle-shaped, and the change is obvious at the top boundary of fractured zone, showing a trend of rapid attenuation.

From the above analysis, it can be seen that, in the case of no gas control measures, the gas concentration in mining overburden is higher as a whole, the high gas area on one side of the return airway is widely distributed, and the upper corner area forms a high gas accumulation area. The gas in the working face, upper corner, and return airway has exceeded the limit seriously; therefore, it is necessary to take targeted measures to control pressure relief gas.

Horizontal gas concentration monitoring lines were arranged on the coal seam roof of 20,40 , and $60 \mathrm{~m}$ layers, respectively, to quantitatively analyze the variation rule of gas concentration in mining-induced fractured zone and master the location distribution of gas accumulation area. The curve of gas concentration change is shown in Figure 10. It can be seen from the figure that the gas concentration in the middle and lower strata of mining overburden varies little within $200 \mathrm{~m}$ from the intake airway and then begins to differ and gradually increases as the distance from the return airway decreases, and the difference is obvious within $50 \mathrm{~m}$ from the return airway. The gas concentration at the upper level $(60 \mathrm{~m})$ of mining overburden is very low on the side close to the intake airway, and the gas concentration on the side close to the return airway rises sharply to the level similar to that at the middle and lower level but decreases rapidly within the range of $50 \mathrm{~m}$ from the return airway. Therefore, the mining-induced overburden below $60 \mathrm{~m}$ and within $50 \mathrm{~m}$ from the return airway is the distribution area of high gas concentration. In summary, the gas accumulation area in mining-induced fractured zone is located within the range of $25 \sim 55 \mathrm{~m}$ from the return airway and $25 \sim 50 \mathrm{~m}$ from the coal seam roof.

\section{High/Low-Level Pressure Relief Gas Directional Drainage of Overburden in Goaf}

5.1. Design of High-Location Directional "Parabolic" Borehole Layout in Early Mining. Aiming at the problem that the roof fissure is not fully developed in the initial mining period and the drainage effect is not ideal in the middle section of the high directional "horizontal" borehole designed by the conventional design, the first group of high roof long boreholes in the working face is designed as a "parabola" to ensure the low pressure relief gas drainage effect of overburden rock in the goaf at the beginning of mining face. According to the previous basic research results, the failure height of overburden in goaf increases gradually during the initial mining period, the height of caving zone develops to $22 \mathrm{~m}$, and the height of fissure zone develops to $75 \mathrm{~m}$. In the first drilling site of the working face, four high directional "parabola" boreholes are designed, of which two boreholes enter the coal seam to be mined at the cut hole, and the pressure relief gas is extracted from the cut hole to the initial pressure period.
Based on the above analysis, the layout parameters of the roof directional "parabola" drilling in the drilling field during the initial mining period are shown in Table 4.

The design trajectory of the high directional "parabola" borehole in the initial mining period of the working face is shown in Figure 11. According to the design parameters, for 1-1 borehole, highest point from roof of coal seam is $44 \mathrm{~m}$, horizontal distance between end point of borehole and working face is $21 \mathrm{~m}$, horizontal distance from end point of borehole to return roadway is $45 \mathrm{~m}$, vertical distance between end point of borehole and roof of coal seam is $29 \mathrm{~m}$; it is $34 \mathrm{~m}, 19 \mathrm{~m}, 32 \mathrm{~m}$, and $19 \mathrm{~m}$ for $1-2$ boreholes; $29 \mathrm{~m}, 0 \mathrm{~m}$, $24 \mathrm{~m}$, and $0 \mathrm{~m}$ for $1-3$ boreholes; and $26 \mathrm{~m}, 0 \mathrm{~m}, 15 \mathrm{~m}$, and $0 \mathrm{~m}$ for 1-4 boreholes.

\subsection{Design of High Directional "Horizontal" Borehole Layout} in the Stable Mining Period. According to the previous research results, the development height of "three zones" is basically stable during the stable mining period, the height of mining overburden caving zone is about $25 \sim 27 \mathrm{~m}$, and the height of fractured zone is about $75 \sim 95 \mathrm{~m}$. The gas accumulation area of mining-induced fractured zone is located in the range of $25 \sim 55 \mathrm{~m}$ away from the return airway and $25 \sim 50 \mathrm{~m}$ from the coal seam roof. This height range is basically in the lower part of the fractured zone and above the caving zone. It is mainly used to mainly store and transport this coal seam mining pressure relief gas and adopts the method of gas drainage by high directional "horizontal" borehole in the fractured zone of coal seam roof.

In order to ensure the gas drainage effect of high level boreholes, combined with the actual situation of the site, a more reasonable arrangement of high level boreholes is obtained through comprehensive analysis, and the data of horizon/offset are shown in Table 5. Four high level boreholes are arranged in each drilling field, with the hole diameter of $133 \mathrm{~mm}$, and the length of the hole is about $500 \mathrm{~m}$. Steel casing is set at $9 \mathrm{~m}$ of the opening section, and the hole is sealed with cement mortar in the way of "two sealing and one grouting" gas hole-sealing technology. The layout of high level boreholes is shown in Figure 12.

\subsection{Test on Effect of Pressure Relief Gas Control}

5.3.1. Effect of Pressure Relief Gas Drainage. The statistics of extraction concentration and purity after high drilling arrangement in working face during initial mining are shown in Figure 13. In addition to the extraction purity of 1-2 boreholes, the extraction purity and concentration of other boreholes show an overall upward trend. The results show that, with the continuous mining of the working face, the cracks in the goaf of the working face develop gradually, and the concentration and flow rate increase gradually due to the conduction of the borehole and fissure. During the whole initial mining period, the gas concentration ranges from $5.6 \%$ to $6.77 \%$, from $5.72 \%$ to $6.91 \%$, from $5.61 \%$ to $7.19 \%$, 


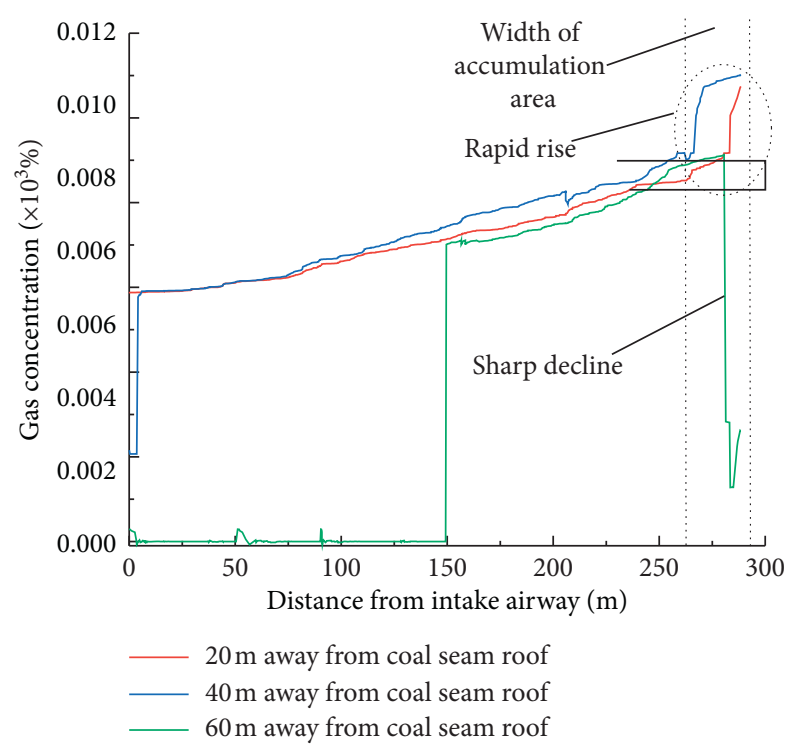

FiguRE 10: Distribution curve of gas concentration in the fractured zone.

TABLE 4: Design parameters of \#1 drilling field.

\begin{tabular}{|c|c|c|c|c|c|c|}
\hline $\begin{array}{l}\text { Drill } \\
\text { field }\end{array}$ & $\begin{array}{c}\text { Hole } \\
\text { number }\end{array}$ & $\begin{array}{l}\text { Highest point } \\
\text { from roof of coal } \\
\text { seam }(\mathrm{m})\end{array}$ & $\begin{array}{l}\text { Horizontal distance } \\
\text { between end point of } \\
\text { borehole and working face } \\
(\mathrm{m})\end{array}$ & $\begin{array}{l}\text { Horizontal distance from } \\
\text { end point of borehole to } \\
\text { return roadway }(\mathrm{m})\end{array}$ & $\begin{array}{l}\text { Vertical distance between } \\
\text { end point of borehole and } \\
\text { roof of coal seam }(\mathrm{m})\end{array}$ & $\begin{array}{c}\text { Drilling } \\
\text { depth }(\mathrm{m})\end{array}$ \\
\hline \multirow{4}{*}{$\# 1$} & $1-1$ & 44 & 21 & 45 & 29 & 300 \\
\hline & $1-2$ & 34 & 19 & 32 & 19 & 300 \\
\hline & $1-3$ & 29 & 0 & 24 & 0 & 312 \\
\hline & $1-4$ & 26 & 0 & 15 & 0 & 306 \\
\hline
\end{tabular}

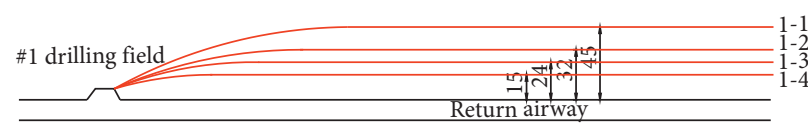

(a)

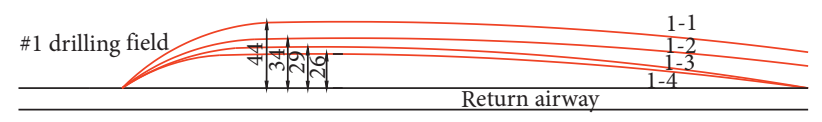

(b)

Figure 11: Design trajectory of high directional "parabola" drilling in \#1 drilling field (m). (a) Floor plan. (b) Section plane.

TABle 5: Parameter of high level drilling arrangement.

\begin{tabular}{lcccc}
\hline Drilling field & Borehole number & $\begin{array}{c}\text { Horizontal distance from return } \\
\text { air roadway }(\mathrm{m})\end{array}$ & $\begin{array}{c}\text { Vertical distance from } \\
\text { coal seam roof }(\mathrm{m})\end{array}$ & $\begin{array}{c}\text { Borehole } \\
\text { length }(\mathrm{m})\end{array}$ \\
\hline \multirow{3}{*}{$\# 3$} & $3-1$ & 50 & 45 & 521 \\
& $3-2$ & 40 & 40 & 511 \\
& $3-3$ & 30 & 32 & 503 \\
& $3-4$ & 20 & 25 & 497 \\
\hline
\end{tabular}

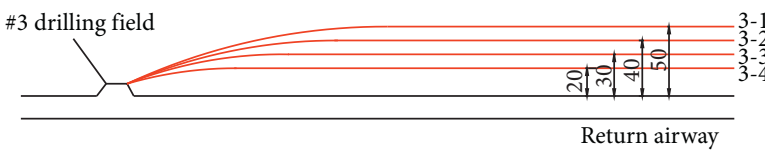

(a)

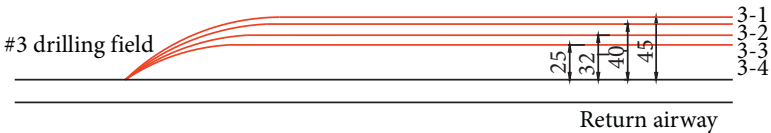

(b)

Figure 12: High directional drilling layout of \#3 drilling site (m). (a) Floor plan. (b) Section plane. 


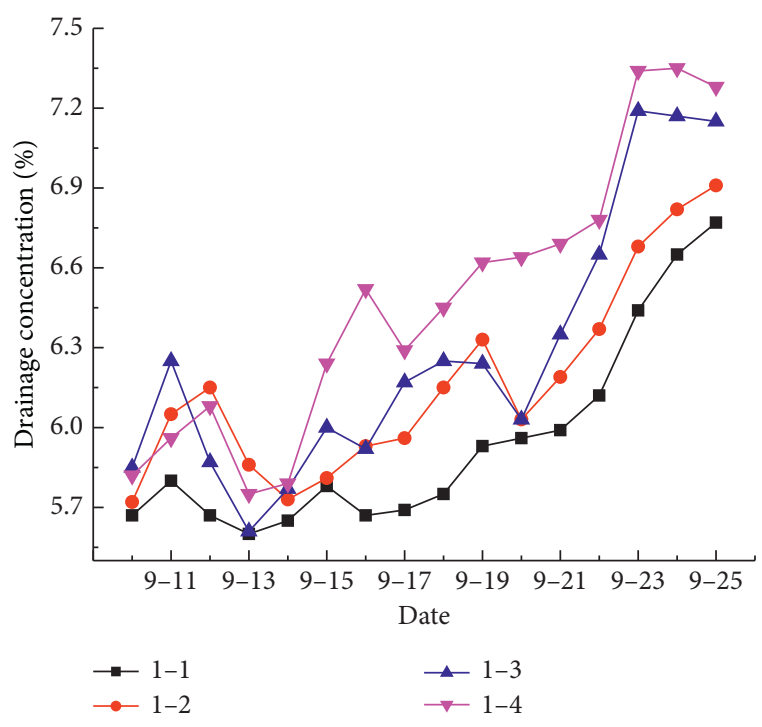

(a)

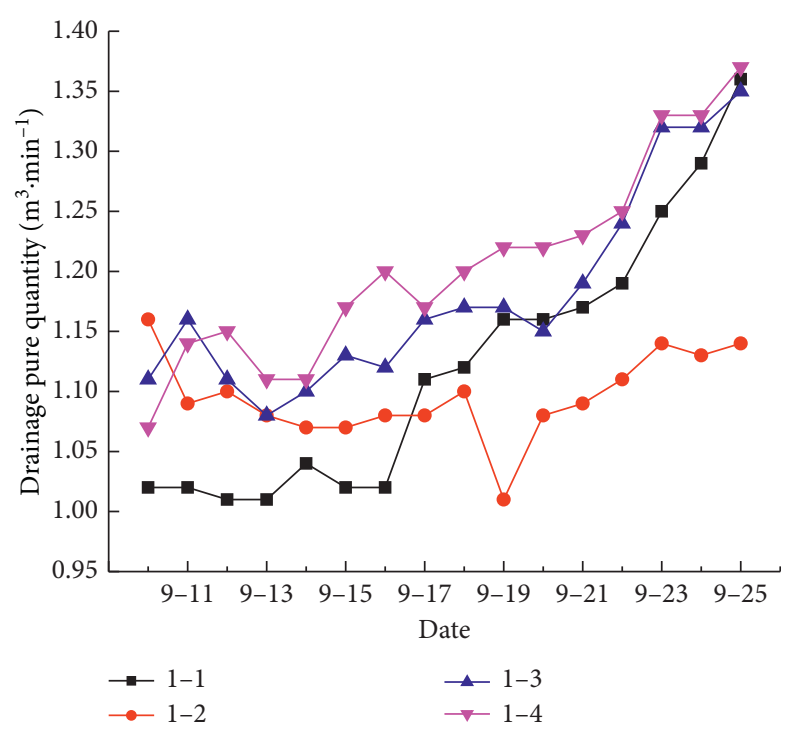

(b)

FIGURE 13: Extraction effect of \#1 high directional long borehole. (a) Drainage concentration. (b) Drainage pure quantity.

and from $5.75 \%$ to $7.35 \%$, the average gas concentration is $5.95 \%, 6.17 \%, 6.28 \%$, and $6.48 \%$, the average drainage purity ranges from 1.01 to $1.36 \mathrm{~m}^{3} / \mathrm{min}$, from 1.01 to $1.16 \mathrm{~m}^{3} / \mathrm{min}$, from 1.08 to $1.35 \mathrm{~m}^{3} / \mathrm{min}$, and from 1.07 to $1.37 \mathrm{~m}^{3} / \mathrm{min}$, and the average extraction purity is $1.12 \mathrm{~m}^{3} / \mathrm{min}, 1.1 \mathrm{~m}^{3} / \mathrm{min}$, $1.18 \mathrm{~m}^{3} / \mathrm{min}$, and $1.2 \mathrm{~m}^{3} / \mathrm{min}$.

The average drainage concentration and pure amount of 1-3 and 1-4 boreholes are higher than those of 1-1 and 1-2 boreholes during the initial mining period. It is shown that the borehole with parabola track is effective and the pressure relief gas accumulated in goaf is effectively extracted.

The statistics of gas extraction concentration and pure quantity of drainage after high level borehole arrangement are shown in Figure 14 and the life cycle of 4 boreholes in \#3 drilling field of working face is from April 1, 2019, to May 29, 2019. It can be seen from Figure 14 that, during this period, the gas extraction concentration and pure quantity of drainage show a trend of decreasing fluctuation. The average gas extraction concentrations of the four boreholes are $4.98 \%, 4.80 \%, 7.69 \%$, and $5.73 \%$, respectively, and the pure quantity of drainage is $0.31,0.35,1.36$, and $0.80 \mathrm{~m}^{3} / \mathrm{min}$, respectively. It can be seen that the gas extraction concentration and pure quantity of drainage of each borehole are relatively high, and the extraction effect is good.

5.3.2. Effect of Gas Control in Working Face. The maximum gas concentration in the upper corner and return air flow of the working face during the initial mining period is shown in Figure 15. It can be seen from Figure 15 that, in the case of gas extraction in goaf, gas in goaf can be drained in time to prevent gas from gushing out to working face. The maximum gas concentration in the upper corner is between $0.12 \%$ and $0.5 \%$, the average gas concentration is $0.36 \%$, the maximum gas concentration in the return air flow is $0.01 \%$ $0.13 \%$, the average gas concentration is $0.06 \%$, and the gas concentration in the upper corner and return air flow is less than $0.8 \%$, which achieves the expected effect of gas treatment in the working face. The working face can be produced safely and efficiently, so it plays an important role in ensuring the safe mining of the working face by using the "parabola" borehole to extract gas during the initial mining period.

The statistics of gas concentration in upper corner and return airway after high level borehole arrangement in working face are shown in Figure 16. The gas concentration in the upper corner of the working face is $0.16 \% \sim 0.78 \%$, and the gas concentration in the return airway is $0.03 \% \sim 0.79 \%$. The gas concentration of working face, upper corner, and return airway is less than $0.8 \%$, so the gas control of working face achieves the expected effect, which can ensure the safety production under this condition.

\section{Discussion}

Mastering the gas distribution characteristics of mining overburden fractured zone is the key to the design of pressure relief gas drainage. In view of the shortcomings of the current splitting researches on the fracture field and gas field, this paper combines researches of the mining fracture distribution with gas migration and uses the coupled mathematical model of mining fracture field and pressure relief gas field to analyze the distribution characteristics of pressure relief gas in mining fracture field. Meanwhile, this paper guides the design of pressure relief gas drainage in overlying strata of goaf and achieves good effect of pressure relief gas control.

In order to solve the problem of gas governance caused by the difference of gas outburst between the initial and the stable mining period, the distribution and evolution characteristics of overburden fissure field in the whole process from cutting hole mining to mining stability are 


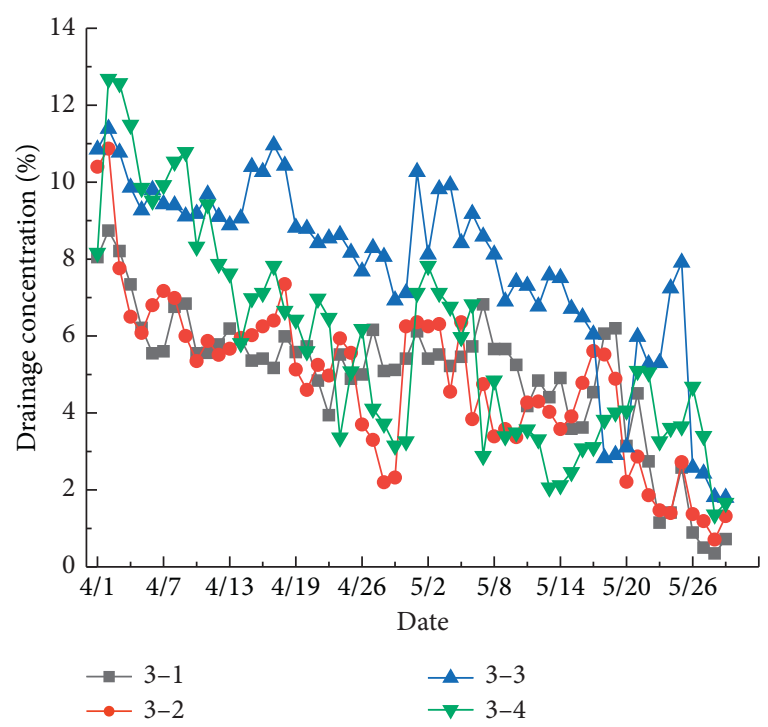

(a)

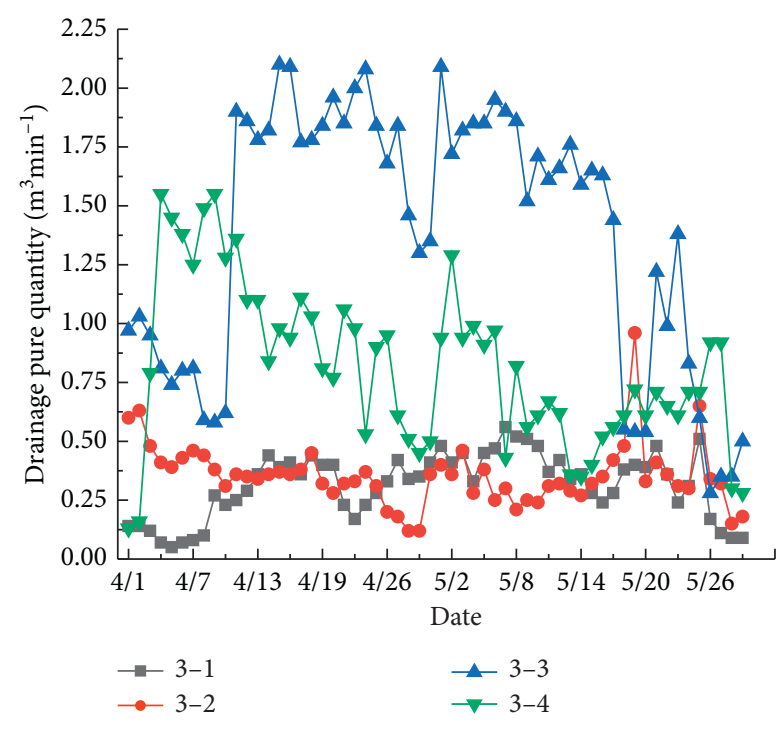

(b)

Figure 14: Extraction effect of \#3 high directional long borehole. (a) Drainage concentration. (b) Drainage pure quantity.

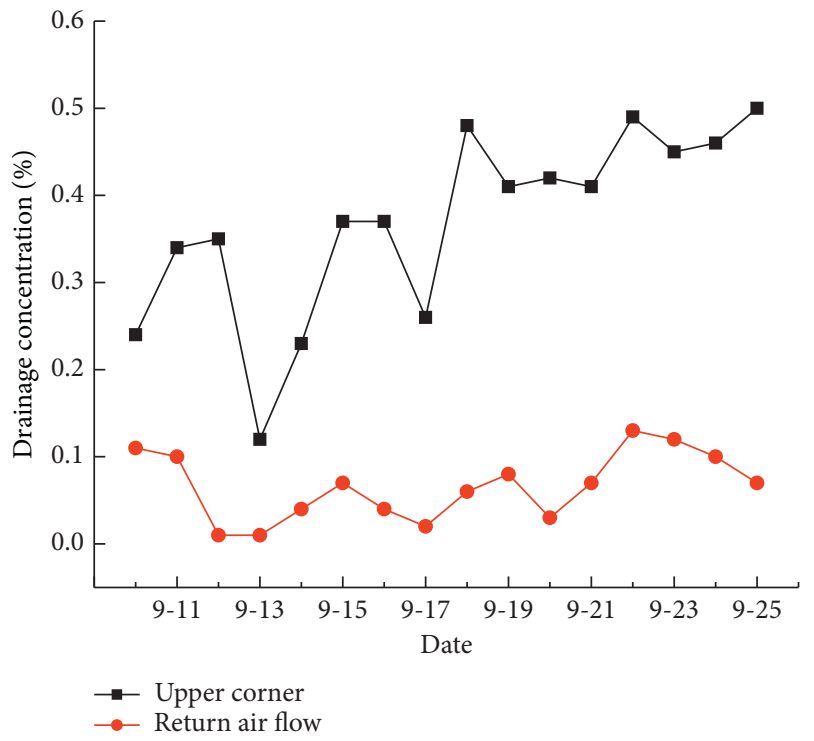

FIGURE 15: Gas concentration in upper corner and return air flow of working face during initial mining.

systematically studied, and the results show the development height and scope of the "three zones" of overlying strata in goaf in the early and stable mining periods, which provide the basis for phased targeted gas control in working face.

In order to further explore the coupling characteristics of mining fracture field and gas field, this paper considers the seepage, uplift, and diffusion characteristics of pressure relief gas in porous media, and a mathematical model of coupling between mining fracture field and pressure relief gas field including state equation, continuity equation, mass conservation equation, motion equation, and migration diffusion equation is established, which provides a basic

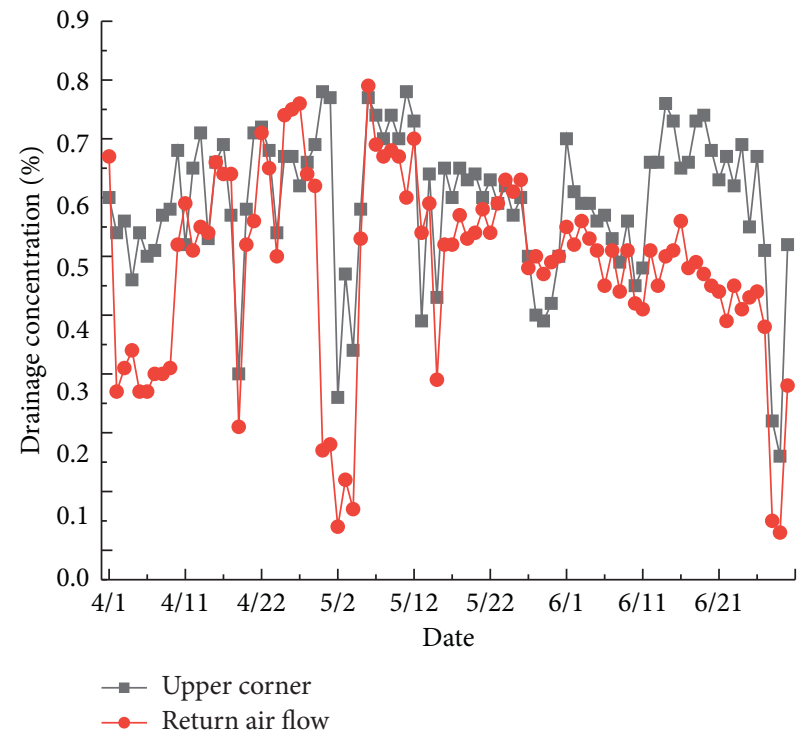

FIGURE 16: Gas concentration in upper corner and return airway of working face.

algorithm for solving the numerical value of solid-gas coupling.

Further, according to the distribution characteristics of mining fracture field and coupling mathematical model, the numerical calculation model of pressure relief gas field distribution considering mining fracture field is established, and the gas distribution and variation characteristics of mining fracture field are analyzed. The distribution location and range of overburden gas enrichment area in goaf are obtained, providing reliable basis for pressure relief gas drainage. 
Finally, based on the distribution characteristics of the gas enrichment area in the mining-induced overburden fissure zone, the layout parameters of the mining pressure relief gas drainage borehole are designed from the initial and the stable stage of mining. The gas drainage effect and gas control effect in the two stages are investigated and analyzed, respectively, which effectively control the gas emission of the working face and ensure the safe production of the working face under the condition of low gas occurrence and highstrength mining.

In this paper, only the high-strength mining conditions of low gas occurrence are systematically studied. For other gas occurrence and mining conditions, the applicability of this method needs further study and textual research. For example, for high gas occurrence coal seam, low permeability coal seam, or outburst coal seam, in addition to using goaf pressure relief gas drainage measures, it is necessary to combine the treatment measures such as increasing permeability and predrainage to ensure the controllable gas emission from the working face and ensure safe mining.

\section{Conclusion}

(1) In the initial stage of mining, the overlying strata structure and fracture activity are relatively large. With the advance of the working face, the mininginduced fractures are developing upward, and the initial pressure and three periodic pressures occurred from the cutting hole to $135 \mathrm{~m}$ in the initial mining period of the working face. The overburden in the goaf showed obvious group movement and coordinated movement characteristics marked by the key layer. The height of collapse zone developed to $22 \mathrm{~m}$, and fracture height developed to $75 \mathrm{~m}$.

(2) The overlying strata structure and fracture activity gradually become stable under the influence of the key stratum in the later stage of mining. A mining fracture network composed of a large number of open and closed fissures is formed, which provides a channel and place for the storage and transportation of pressure relief gas. The height of the "three zones" is $25 \sim 27 \mathrm{~m}$ in the caving zone, $75 \sim 95 \mathrm{~m}$ in the fractured zone, and $110 \mathrm{~m}$ in the curve subsidence zone, respectively.

(3) Using Darcy fissure flow equation and NavierStokes equation and convection diffusion equation of pore medium, the numerical model of pressure relief gas flow in mining fissure field is constructed, and the process and distribution of pressure relief gas flow in goaf are obtained by solving the model.

(4) Under the influence of air flow, the pressure relief gas mainly distributes in the mining-induced fractured zone near the return airway and accumulates near the upper corner. With the passage of time, the gas concentration on the side of the return airway in fractured zone increases gradually and forms a high concentration gas accumulation with the upper corner area. The gas accumulation area is located in the range of $25 \sim 55 \mathrm{~m}$ away from the return airway and $25 \sim 50 \mathrm{~m}$ from the coal seam roof.

(5) After the implementation of high level directional drilling gas drainage technology, the high concentration gas gathering in the mining-induced fractured zone and upper corner area of the working face has been well controlled. The maximum gas concentration in the upper corner and return airway is not more than $0.8 \%$. The pressure relief gas control has achieved good results, ensuring the safe and efficient production of the working face.

\section{Data Availability}

The data used to support the findings of this study are available from the corresponding author upon request.

\section{Conflicts of Interest}

The authors declare no conflicts of interest.

\section{Acknowledgments}

This research was financially supported by the National Natural Science Foundation of China (51874314, 51774292, 51604278, and 51804312) and the Yue Qi Young Scholar Project, China University of Mining and Technology, Beijing.

\section{References}

[1] C. Otto and T. Kempka, "Thermo-mechanical simulations of rock behavior in underground coal gasification show negligible impact of temperature-dependent parameters on permeability changes," Energies, vol. 8, no. 6, pp. 5800-5827, 2015.

[2] F. Gao, D. Stead, and J. Coggan, "Evaluation of coal longwall caving characteristics using an innovative UDEC Trigon approach," Computers and Geotechnics, vol. 55, no. 55, pp. 448-460, 2014.

[3] J. Liu, Z. Liu, J. Xue, K. Gao, and W. Zhou, "Application of deep borehole blasting on fully mechanized hard top-coal presplitting and gas extraction in the special thick seam," International Journal of Mining Science and Technology, vol. 25, no. 5, pp. 755-760, 2015.

[4] Y. Lu, L. Cheng, Z. Ge, B. Xia, Q. Li, and J. Chen, "Analysis on the initial cracking parameters of cross-measure hydraulic fracture in underground coal mines," Energies, vol. 8, no. 7, pp. 6977-6994, 2015.

[5] J. Cao and W. Li, "Numerical simulation of gas migration into mining-induced fracture network in the goaf," International Journal of Mining Science and Technology, vol. 27, no. 4, pp. 681-685, 2017.

[6] H. Guo, L. Yuan, B. Shen, Q. Qu, and J. Xue, "Mining-induced strata stress changes, fractures and gas flow dynamics in multi-seam longwall mining," International Journal of Rock Mechanics and Mining Sciences, vol. 54, no. 3, pp. 129-139, 2012.

[7] K. Wang and F. Du, "Coal-gas compound dynamic disasters in China: a review," Process Safety and Environmental Protection, vol. 133, pp. 1-17, 2020.

[8] H. Wang, X. Fang, Y. Li, Z. Zheng, and J. Shen, "Research and application of the underground fire detection technology 
based on multi-dimensional data fusion," Tunnelling and Underground Space Technology, vol. 109, Article ID 103753, 2021.

[9] H. Wang, S. Guo, Y. Xie, H. Zhao, H. Wang, and W. Wang, "Study on competitive adsorption characteristics of $\mathrm{CO} / \mathrm{CO} 2 /$ CH4 multi-component low concentration gases in coal," Energy Sources, Part A: Recovery, Utilization, and Environmental Effects, 2020.

[10] Y. Liang, "Control of coal and gas outbursts in Huainan mines in China: a review," Journal of Rock Mechanics and Geotechnical Engineering, vol. 8, no. 4, pp. 559-567, 2016.

[11] H. Wang, B. Tan, Z. Shao, Y. Guo, Z. Zhang, and C. Xu, "Influence of different content of $\mathrm{FeS} 2$ on spontaneous combustion characteristics of coal," Fuel, vol. 288, Article ID 119582, 2021.

[12] J. Zhang, N. Chen, G. Yan, and Y.-C. Kim, "The safety attitudes of senior managers in the Chinese coal industry," International Journal of Environmental Research and Public Health, vol. 13, no. 11, p. 1147, 2016.

[13] C. Xin, F. Du, K. Wang et al., "Damage evolution analysis and gas-solid coupling model for coal containing gas," Geomechanics and Geophysics for Geo-Energy and Geo-Resources, vol. 7, no. 7, 2021.

[14] K. Wang, Y.-M. Wei, and X. Zhang, "Energy and emissions efficiency patterns of Chinese regions: a multi-directional efficiency analysis," Applied Energy, vol. 104, no. 2, pp. 105-116, 2013.

[15] Y. Du, X. Chen, L. Li, and P. Wang, "Characteristics of methane desorption and diffusion in coal within a negative pressure environment," Fuel, vol. 217, pp. 111-121, 2018.

[16] C. Zhang, J. Xu, S. Peng, Q. Li, and F. Yan, "Experimental study of drainage radius considering borehole interaction based on 3D monitoring of gas pressure in coal," Fuel, vol. 239, pp. 955-963, 2019.

[17] G. Wang, Y. Liu, and J. Xu, "Short-term failure mechanism triggered by hydraulic fracturing," Energy Science and Engineering, vol. 8 , no. 3, pp. 92-601, 2020

[18] Q. Li, J. Xu, F. Yan, S. Peng, C. Zhang, and X. Zhang, "Evolution characteristics of reservoir parameters during coalbed methane drainage via in-seam horizontal boreholes," Powder Technology, vol. 362, pp. 591-603, 2020.

[19] K. Jin, Y. Cheng, T. Ren et al., "Experimental investigation on the formation and transport mechanism of outburst coal-gas flow: implications for the role of gas desorption in the development stage of outburst," International Journal of Coal Geology, vol. 194, pp. 45-58, 2018.

[20] C. Zhang, J. Xu, S. Peng, X. Zhang, X. Liu, and Y. Chen, "Dynamic evolution of coal reservoir parameters in CBM extraction by parallel boreholes along coal seam," Transport in Porous Media, vol. 124, no. 2, pp. 325-343, 2018.

[21] Y. Cheng, Y. Lu, Z. Ge, L. Cheng, J. Zheng, and W. Zhang, "Experimental study on crack propagation control and mechanism analysis of directional hydraulic fracturing," Fuel, vol. 218, pp. 316-324, 2018.

[22] C. Zhang, J. Xu, S. Peng, Q. Li, F. Yan, and Y. Chen, "Dynamic behavior of gas pressure and optimization of borehole length in stress relaxation zone during coalbed methane production," Fuel, vol. 233, pp. 816-824, 2018.

[23] C. Zhang, L. Zhang, S. Tu, D. Hao, and T. Teng, "Experimental and numerical study of the influence of gas pressure on gas permeability in pressure relief gas drainage," Transport in Porous Media, vol. 124, no. 3, pp. 995-1015, 2018.

[24] F. Wang, J. He, Y. Liang, Y. Luo, Z. Liao, and L. Li, "Study on the permeability characteristics of coal containing coalbed methane under different loading paths," Energy Science \& Engineering, vol. 6, no. 5, pp. 475-483, 2018.

[25] C. Zhang, J. Xu, G. Yin, S. Peng, Q. Li, and Y. Chen, "A novel large-scale multifunctional apparatus to study the disaster dynamics and gas flow mechanism in coal Mines," Rock Mechanics and Rock Engineering, vol. 52, no. 8, pp. 28892898, 2019.

[26] M. Shabanimashcool and C. C. Li, "Numerical modelling of longwall mining and stability analysis of the gates in a coal mine," International Journal of Rock Mechanics and Mining Sciences, vol. 51, no. 4, pp. 24-34, 2012.

[27] H. Zhang and Y. Huang, "Flow field and gas concentration distribution in the coal mining face and mined-out area with J-Shape and U-Shape ventilation system using Comsol," Journal of Physics: Conference Series, vol. 1168, Article ID 052041, 2019

[28] S. G. Li, H. F. Lin, P. X. Zhao et al., "Dynamic evolution of mining fissure elliptic paraboloid zone and extraction coal and gas," Journal of China Coal Society, vol. 39, no. 8, pp. 14551462, 2014. 